This item was submitted to Loughborough's Research Repository by the author.

Items in Figshare are protected by copyright, with all rights reserved, unless otherwise indicated.

\title{
Biomineralization of Pd nanoparticles using Phanerochaete chrysosporium as a sustainable approach to turn platinum group metals (PGMs) wastes into catalysts
}

\section{PLEASE CITE THE PUBLISHED VERSION}

https://doi.org/10.1016/j.ibiod.2019.104724

\section{PUBLISHER}

Elsevier

\section{VERSION}

AM (Accepted Manuscript)

\section{PUBLISHER STATEMENT}

This paper was accepted for publication in the journal International Biodeterioration \& Biodegradation and the definitive published version is available at https://doi.org/10.1016/j.ibiod.2019.104724.

\section{LICENCE}

CC BY-NC-ND 4.0

\section{REPOSITORY RECORD}

Tarver, Sophie, Daniel Gray, Konstantin Loponov, Diganta Das, Tao Sun, and Maria Sotenko. 2019.

"Biomineralization of Pd Nanoparticles Using Phanerochaete Chrysosporium as a Sustainable Approach to Turn Platinum Group Metals (pgms) Wastes into Catalysts". Loughborough University.

https://hdl.handle.net/2134/12327956.v1. 


\title{
Biomineralization of Pd nanoparticles using Phanerochaete chrysosporium as a sustainable
} approach to turn platinum group metals (PGMs) wastes into catalysts

\author{
Sophie Tarver, Daniel Gray, Konstantin Loponov, Diganta B. Das, Tao Sun, Maria Sotenko* \\ Department of Chemical Engineering, Loughborough University, Loughborough LE11 3TU, \\ Leicestershire, United Kingdom

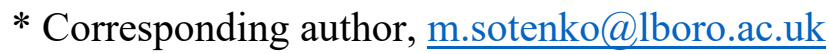

\begin{abstract}
Due to the increasing demand for recovery of precious metals from waste streams, the role of fungus as a potential adsorbent is growing. Thus, this research aimed to develop a novel method for the biomineralization of palladium nanoparticles using Phanerochaete chrysosporium fungus. The adsorption of palladium onto the fungal mycelium was studied by adding palladium salt at 12$48 \mathrm{ppm}$ to the fermentation medium following the fungal growth. Amide groups of chitin and proteins on the surface of the fungus are believed to coordinate palladium cations yielding Freundlich-type competitive adsorption isotherm. The adsorption capacity was found to reach 22$128 \mathrm{mgPd} \mathrm{g}^{-1}$ of dried fungal biomass. Biomineralization of palladium from an aqueous solution led to the formation of extracellular well defined Pd nanoparticles of 10-14 nm confirmed by XPS, TEM and XRD analyses. The biologically synthesised nanoparticles were found to perform equally well to a $\mathrm{Pd} / \mathrm{C}$ commercial catalyst in a Heck reaction of styrene and iodobenzene. This is the first reported use of Phanerochaete chrysosporium to synthesise palladium nanoparticles and confirmation of their resulting catalytic activity. The presented example paves the way for the development of fungi-based membranes to be used in the palladium recovery from industrial effluents.
\end{abstract}

\section{Introduction}

Biotechnology has recently found some novel non-traditional applications and bio-mineralization is one of those examples (Addadi \& Weiner 2014; Rawlings et al. 2003; Weiner 2003; Gadd 2010). Bio-mineralization, i.e., the production of minerals or metal clusters via microorganisms, is especially useful in those cases where rare-earth elements or high value metals need to be recovered from industrial waste streams. There have been some biotechnological approaches developed with the main aim to recover platinum group metals, gold, silver and some lanthanides (Zhuang et al. 2015; Gherghe 2017; Das \& Das 2013; Nancharaiah et al. 2016). Moreover, in those cases where metallic nanoparticles (NPs) are formed as the result of bio-mineralization process, one can achieve multiple benefits, such as the production of value-added products in addition to solving the environmental problem of water streams contaminated with otherwise toxic metals. Some examples include biotechnological methods for the production of antimicrobial AgNPs (Siddiqi et al. 2018; Saklani \& Jain 2013), AuNPs used widely in bioimaging and labelling (Menon et al. 2017; Lengke et al. 2011; Zhao et al. 2013; Qin et al. 2018), bio-Pd catalytic nanoparticles (Deplanche et al. 2014; Bennett et al. 2013; Zhu et al. 2016) and even quantum dots (Qin et al. 2018; Mary et al. 2018). 'Green' biosynthesis methods for the production of nanoparticles offer some benefits in comparison to the traditional wet chemistry approaches such as mild reaction conditions and the use of environmentally friendly biocatalysts and non-toxic chemicals. Thus, the biotechnological methods eliminate the need for toxic and corrosive reducing agents, such as 
sodium borohydride which is widely used in chemical methods and requires safe handling and disposal (ThermoFisher Scientific 2010). Moreover, chemical synthesis of metallic nanoparticles usually takes place in two steps, i.e., the initial formation of the nanoparticles followed by the addition of an encapsulating agent to prevent the nanoparticles from agglomeration (Cookson 2012). A biological method, however, does not require any encapsulating agents as the enzymes released by the microorganisms are believed to prevent the agglomeration of the nanoparticles (Sanghi et al. 2011; Zielonka \& Klimek-Ochab 2017).

The majority of the reported biotechnological methods have been directed towards using bacteria for the synthesis of nanoparticles (Saklani \& Jain 2013; Lengke et al. 2011; Menon et al. 2017; Narayanan \& Sakthivel 2011; Guil-Guerrero et al. 2016; Edmundson et al. 2014; Cueva \& Horsfall 2017). However, the bacterial nanoparticles are formed mainly intracellularly and the extraction of these nanoparticles leads to high processing costs. The costs are further increased by the required genetic modification of the available strains in order to overcome metal toxicity in bacteria. Fungal route, on the contrary, could offer some advantages in comparison to the bacterial methods. Firstly, when synthesized by fungi, the nanoparticles form extracellularly and therefore do not require the additional stage of biomass disruption to release the intracellular bacterial nanoparticles (Conesa et al. 2009). Secondly, fungal route does not require an electron donor eliminating the need for hydrogen atmosphere which is essential in bacterial processes (Deplanche et al. 2014; Bennett et al. 2013; Zhu et al. 2016). Thirdly, fungi were reported to have a higher tolerance to metal uptake and increased wall binding capacity in comparison to bacteria (Chen et al. 2009). Finally, fungi as the biological support for the nanoparticles offer an advantage of higher biomass yield and surface area due to their filamentous network structures. Because of all these advantages, the interest in biomineralization has recently shifted towards replacing bacteria with fungi to enable the bioderivation of nanoparticles to be a promising alternative to chemical reduction methods (Saxena et al. 2014).

Despite the great interest in the fungal bio-mineralization, the range of the reported metals is still limited. The majority of the reports on fungal synthesis of nanoparticles is mainly devoted to the biomineralization of silver and gold (Saxena et al. 2014; Menon et al. 2017; Siddiqi et al. 2018). There seems to be no preference for a specific fungus in these processes although Fusarium oxyporum, Aspergillus genus and Aspergillus niger in particular are the most commonly used fungi (Moghaddam et al. 2015; Zielonka \& Klimek-Ochab 2017; Kitching et al. 2015). The synthetic method could be based either on the use of mycelia-free fungal supernatant or co-incubation of the metal ions with the submerged fungal cultures, mainly after the fungal growth stage. The majority of the reported AuNPs and AgNPs are characterized as extracellular, spherical in shape and having high stability against agglomeration and a wide range of sizes from 5 to $100 \mathrm{~nm}$ (Moghaddam et al. 2015; Zielonka \& Klimek-Ochab 2017; Kitching et al. 2015). Along with various bioactive compounds present in the medium and secreted by fungi, enzymes are regarded as the main stabilizing and reducing agents in the production of nanoparticles. Based on enzyme assays, Sanghi et al. attributed the fungus activity to laccase and ligninase in a reported synthesis of gold nanoparticles with $P$. chrysosporium (Sanghi et al. 2011). In addition to stabilizing effect, it was shown that the fungal extract possesses shape-forming properties in the synthesis of multi-shaped gold nanoparticles using a cell-free extract from Rhizopus oryzae fungus (Das et al. 2010).

Despite these advantages, the fungal route has not been used for platinum group metals (PGMs), which are known to be used in an incredibly wide range of applications, including catalytic converters, pharmaceuticals, diagnostic and bulk chemicals synthesis (Godwin et al. 2015; Heera 
\& Shanmugam 2015; Zhao et al. 2013; Siddiqi \& Husen 2016). Unfortunately, the increasing demand for PGMs is accompanied by exhaustion of the current supply. According to JohnsonMatthey's most recent report, the worldwide supply deficit of palladium in 2017 was 629,000 oz and as a result the price of palladium rose by $51 \%$ (Johnson Matthey 2018). Despite the fact that one third of palladium is recycled, there is still a need to develop a cost-effective method to recover palladium from industrial effluents. Therefore, this study aimed to verify the ability of the fungus $P$. chrysosporium to biomineralise $\mathrm{Pd}$ from aqueous solutions with the main drive to further develop the fungi loaded membranes for the recovery of Pd from waste waters.

P. chrysosporium has demonstrated exceptional adsorption properties and has been previously widely used for the effective removal of heavy metals from waste waters (Yetis et al. 2000; Zhao et al. 2016; Marandi et al. 2008). It is hypothesized, that the advantages of the fungal synthesis of nanoparticles coupled with the fungal unique adsorptive properties will open new possibilities in developing novel metal remediating techniques based on the fungi loaded membranes. In the current paper, the adsorption of Pd from an aqueous solution was investigated; the obtained $\mathrm{Pd}$ nanoparticles were studied using various physico-chemical techniques such as X-ray photoelectron spectroscopy (XPS), transmission electron microscopy (TEM), Fourier-transform infrared spectroscopy (FTIR) and scanning electron microscope (SEM); the catalytic activity of the biosynthesised palladium nanoparticles was also compared to that of a $\mathrm{Pd} / \mathrm{C}$ catalyst in the $\mathrm{Heck}$ reaction as a model catalytic reaction of high industrial relevance.

\section{Materials and Methods}

\subsection{Chemicals}

Potassium hexachloropalladate (IV) (99\%), $1000 \mathrm{mgL}^{-1}$ palladium atomic absorption spectroscopy (AAS) standard, mesitylene (98\%), isopropanol (99.9\%), dimethylformamide (99.8\%, anhydrous), trimethylamine (>99.5\%), styrene (>99\%), iodobenzene $(98 \%), 5 \% \mathrm{Pd} / \mathrm{C}$ commercial catalyst, potassium dihydrogen orthophosphate (99\%), ammonium chloride (99\%), magnesium sulphate ( $>99.5 \%)$, calcium chloride dihydrate $(99 \%)$ were all purchased from Sigma Aldrich or Fischer Scientific and used without prior purification. Malt extract agar (CM0059) and D-glucose anhydrous were procured from Oxoid ltd (UK). For the metal adsorption experiments, aqueous stock solutions of $1000 \mathrm{ppm}$ palladium (IV) was prepared by dissolving $0.09360 \mathrm{~g}$ of potassium hexachloropalladate (IV) in $25 \mathrm{ml}$ of distilled water.

\subsection{Fungal cultures}

An enriched spore solution of the white rot fungus $P$. chrysosporium stored at $-80{ }^{\circ} \mathrm{C}$ in $20 \% \mathrm{v} / \mathrm{v}$ glycerol stock solution was used as the inoculum. The fungus was re-cultured from the spore solution spread on the surfaces of malt extract agar plates in a static incubator (Stuart Scientific Orbital Incubator SI50) at $37^{\circ} \mathrm{C}$ for 5 days. The spore solution was collected as the fresh inoculum by adding $5 \mathrm{ml}$ of sterile distilled water into each of the Petri dishes and scraping the spores from the agar surfaces. The spore content was determined using BRAND ${ }^{\mathrm{TM}}$ Neubauer counting chamber (Fischer Scientific ltd) after appropriate dilution. The broth for fungal culture was composed of $2.0 \mathrm{gL}^{-1} \mathrm{KH}_{2} \mathrm{PO}_{4}, 0.5 \mathrm{gL}^{-1} \mathrm{MgSO}_{4}, 0.1 \mathrm{gL}^{-1} \mathrm{CaCl}_{2}$ with $10 \mathrm{gL}^{-1}$ glucose as carbon source and 0.12 $\mathrm{gL}^{-1} \mathrm{NH}_{4} \mathrm{Cl}$ as nitrogen source and supplemented with $0.001 \mathrm{gL}^{-1}$ of thiamine using a filter-sterile stock solution (Yetis et al. 2000). The $\mathrm{pH}$ of the medium was adjusted to 4.5 prior to autoclaving at $121{ }^{\circ} \mathrm{C}$ for $15 \mathrm{~min}$. The fungus was cultured in $50 \mathrm{ml}$ sterile centrifuge tubes each with $19 \mathrm{ml}$ broth inoculated with $1 \mathrm{ml}$ fresh inoculum $\left(5 \times 10^{7} \mathrm{CFUmL}^{-1}\right)$ in a shaking incubator at $37^{\circ} \mathrm{C}$ and 
$80 \mathrm{rpm}$ for 5 days. The cultures were conducted in triplicates and the fungal growth rate was determined to be $0.11 \pm 0.01 \mathrm{~g}$ of dried biomass per L of the medium per day.

\subsection{Adsorption of palladium by the fungal biomass}

Pd stock solution (1000 ppm) was added into the fermentation medium after 5 days of the fungal culture under sterile conditions to adjust the concentration of palladium within the range of 12-48 $\mathrm{ppm}$. The fungus was further cultured in the shaking incubator at $37^{\circ} \mathrm{C}$ and $80 \mathrm{rpm}$ for another 2 days. The Pd concentration in the fermentation medium was measured using AAS analysis during culture. After culture, the broth was centrifuged at $3500 \mathrm{rpm}$ for 20 minutes using a Thermo Scientific Heraeus Labofuge 400 Centrifuge and the supernatant was discarded. The recovered fungal biomass was washed twice with $20 \mathrm{ml}$ of $75 \% \mathrm{v} / \mathrm{v}$ aqueous ethanol and finally freeze-dried using SciQuip S Christ Alpha 1-2 LD plus freeze dryer until constant weight. The amount of the adsorbed $\mathrm{Pd}$ (or sorption capacity) was expressed either in $\mathrm{mg}_{\mathrm{Pd}}$ per $\mathrm{g}$ of dried biomass or in $\% \mathrm{WPd}_{\mathrm{Pd}} / \mathrm{w}_{\text {biomass }}$ (WPd: palladium weight, $\mathrm{w}_{\text {biomass: }}$ weight of dried fungal biomass) and was obtained based on triplicate samples. The stock solution of Pd was also added into the freshly prepared fermentation medium free of the fungus or the fungi-free supernatant obtained from the broth after 5 days' fungal culture as the control experiments. A fungal culture without palladium salt was also carried out to verify the inhibitory effect of potassium hexachloropalladate on the fungal growth. The Freundlich model was applied for the adsorption experiments using the following correlation:

$$
q=K_{F} C_{e q}^{1 / n}
$$

where $\mathrm{q}\left(\% \mathrm{WPd}_{\mathrm{Pd}} / \mathrm{w}_{\text {biomass }}\right)$ is the palladium uptake by the biomass at equilibrium concentration of palladium $\mathrm{C}_{\mathrm{eq}}(\mathrm{ppm})$ in the solution, $\mathrm{K}_{\mathrm{F}}$ and $\mathrm{n}$ are Freundlich's constants of adsorption capacity and intensity accordingly (Maheswari et al. 2016).

\subsection{Testing of bio-derived palladium nanoparticles in Heck reaction}

Heck reaction was used as a model $\mathrm{C}-\mathrm{C}$ coupling reaction to test the catalytic activity of Pd-loaded fungal biomass in comparison to commercial catalyst of $5 \% \mathrm{Pd} / \mathrm{C}$. The method was modified from (Fan et al. 2009). Briefly, in a $25 \mathrm{ml}$ glass flask, $2 \mathrm{ml}$ of the solvent (dimethylformamide, DMF) was added first, followed by the addition of $1.55 \mathrm{mmol}$ of iodobenzene, $3.76 \mathrm{mmol}$ of trimethylamine (TEA) and $0.854 \mathrm{mmol}$ of mesitylene which was used as a GC internal standard. After the final addition of $2.37 \mathrm{mmol}$ of styrene, the solution was then made up with DMF to obtain $5 \mathrm{ml}$ of the final total volume of the reaction mixture. The molar ratios of styrene:iodobenzne, TEA:iodobenzene and mesitylene:iodobenzene were 1.5, 2.4 and 0.55 respectively. The catalyst concentration was taken in such quantities so as to obtain $0.5 \% \mathrm{molpd}_{\mathrm{Pd}} / \mathrm{mol}_{\text {styrene. Thus, }} 0.0155 \mathrm{~g}$ of $5 \% \mathrm{Pd} / \mathrm{C}$ and the appropriate amount of $4.9 \% \mathrm{Pd} /$ fungi was used in the experiment. After addition of the catalyst, the solution was deoxygenized by purging for 30 minutes with $\mathrm{N}_{2}$ and the reaction was allowed to proceed at $120^{\circ} \mathrm{C}$ and $180 \mathrm{rpm}$ for 3 hours on a hot stirrer plate. Gas chromatographic (GC) analysis was used to monitor the concentration of styrene in the reaction medium and for that $0.1 \mathrm{ml}$ samples were withdrawn from the reaction medium at regular time intervals, mixed with $1 \mathrm{ml}$ of isopropanol and filtered through $0.2 \mu \mathrm{m}$ PTFE filters for further analysis. A control experiment without any catalyst was also conducted for comparison purposes.

\subsection{Analytical and characterization techniques}


The morphology of the fungi was attained using Scanning Electron Microscope (SEM) (JEOL JSM-7800F). The dried fungal samples were mounted onto aluminum stubs using double-sided carbon tape, sputter coated with 80:20 of gold and palladium using a Quorum Q150RS machine and then monitored using SEM. The reduction of palladium was studied using X-ray photoelectron spectroscopy (XPS) on a K-Alpha XPS spectrometer (Thermo Fischer Scientific, UK). The X-ray source was Aluminium K-Alpha $(1.486 .68 \mathrm{eV})$. The surface groups for the fungal biomass before and after the adsorption of palladium were studied using FTIR method in ATR mode (Shimadzu IR Tracer-100). A resolution of $2 \mathrm{~cm}^{-1}$ was averaged over 48 scans. The composition of the Heck reaction samples was analysed using an Agilent Technologies gas chromatograph (7890A). Flame ionization detector (FID) detector was used with a Rtx-65TG column $(0.1 \mu \mathrm{m}$ diameter, $30 \mathrm{~m}$ length and coated with a diphenyl dimethyl polysiloxane resin). The analysis parameters were as follows: $151.71 \mathrm{mLmin}^{-1}$ flow rate, 50:1 split ratio and $1 \mu \mathrm{L}$ sample volume. A Varian SpectrAA 55B Atomic absorption spectrometer was used to determine the soluble palladium species in aqueous solutions. A calibration curve was plotted in the range of 0-100 ppm Pd using AAS standard solution. X-ray diffraction analysis (XRD) was used to determine the crystalline structure of the nanoparticles formed. The samples were analysed by PANalytical Empyrean X-ray diffractometer using $\mathrm{Co} \mathrm{K}_{\alpha}$ radiation $(\lambda=1.78901 \dot{A})$, the scanning range $(2 \theta)$ was between $5^{\circ}-90^{\circ}$ angles with a scanning speed of $1.33^{\circ} \mathrm{min}^{-1}$. It was operated at a voltage of $45 \mathrm{kV}$ and $40 \mathrm{~mA}$ current. TEM images of the gold-coated samples of fungi were obtained using a JEM-2000FX Jeol $200 \mathrm{kV}$ microscope equipped with Gatan Orius camera. The image analysis software ImageJ was used on TEM images to generate the particle size distribution of the palladium nanoparticles.

\section{Results and discussion}

\subsection{Study of Pd adsorption by P. chrysosporium}

The adsorption experiments using $P$. chrysosporium were conducted with a model aqueous solution of $\mathrm{Pd}(\mathrm{IV})$ prepared with $\mathrm{K}_{2} \mathrm{PdCl}_{6}$ salt. A simple procedure for the adsorption of palladium onto the fungi was used where the fungi were first cultured for 5 days prior to the addition of Pd (IV) salt to the fermentation medium. It is worth noting that, the addition of $\mathrm{Pd}^{4+}$ salt at a concentration of 12-48 ppm did not cause any inhibitory effect on the fungal growth as the final biomass yield in 7 days for both control and metal-added samples was $0.80 \pm 0.02 \mathrm{~g} \mathrm{~L}^{-1}$. In contrary, previously it has been reported that tellurium and selenium were found to be inhibitory for the growth of $P$. chrysosporium at a concentration as low as $10 \mathrm{ppm}$ indicating selectivity in the inhibitory effects of various metals onto the fungi (Espinosa-Ortiz et al. 2017). The selectivity in tolerance of $P$. chrysosporium towards various metals has been observed before where it demonstrated endurance to $200 \mathrm{ppm}$ of lead but was inhibited by $16 \mathrm{ppm}$ of cadmium (Zhao et al. 2016).

The adsorption of palladium onto the fungi was easily followed. Thus, during the adsorption experiments, the brown solution of $\mathrm{Pd}^{4+}$ gradually cleared, while the fungal mycelium changed from white to dark grey indicating the adsorption (and reduction) of palladium onto the fungi (Fig. 1 , left, a-c). The gradual reduction in palladium concentration in the solution was also confirmed by AAS analysis. It is worth mentioning that one off experiment with Pd (II) salt was attempted but was accompanied by hydrolysis of $\mathrm{Pd}\left(\mathrm{NO}_{3}\right)_{2}$ upon addition to the fermentation medium which caused precipitation of insoluble Pd hydroxy species. Thus, a special attention needs to be paid to the state and coordination of the metal itself which might undergo modifications upon reaction with the components of the medium. 
The curves expressing the adsorption kinetics of palladium uptake onto the fungus from an the first 5 hours where the concentration of palladium in the solution reduces by $40 \%$ and (2) slow adsorption rate for the following 43 hours where the palladium removal efficiency reaches 81.5 $\%$. The same two-staged process was previously observed for lead uptake by $P$. chrysosporium which was explained by fast surface adsorption and slow intracellular diffusion of the metal ions (Yetis et al. 2000). The adsorption isotherm and its linearised form built from the available data across various concentrations of the initial palladium (Fig. 1, right) indicate that the adsorption kinetics is best described by the Freundlich model, which, however hints that there is a competitive adsorption of other species (presumably, metals from the fermentation medium) onto the surface of the fungus. Overall, Langmuir isotherm is more commonly reported in the literature on adsorption properties of various fungi (Maheswari et al. 2016; Marandi et al. 2008).

Table 1 summarises the data from the adsorption experiments with different initial concentrations of palladium and shows that for the studied range of palladium concentration between 12-48 ppm, the final adsorption efficiency reaches $63.4-81.5 \%$ where higher initial palladium content yielded somewhat higher adsorption efficiency.

It is worth noting, that the initial palladium content was kept low in the current set of experiments and optimized in regards to the fungal biomass yield. Within the studied range, the final palladium loading onto the fungal biomass increased with higher Pd content in the solution and ranged within $2.2-12.8 \% \mathrm{WPd} /$ Wbiomass. This corresponds to $22-128 \mathrm{mg}_{\mathrm{Pd}} \mathrm{g}^{-1}$ biomass which was determined using both AAS and XPS (XPS accuracy is somewhat lower as seen in Table 1). Similarly, the efficiency of removal attained by $P$. chrysosporium in extracting metals from waste waters has been studied in respect to lead, zinc, cadmium, selenium and tellurium ions and sorption capacity was reported to vary between 56-110 mg metal per g biomass dry weight (Yetis et al. 2000; Espinosa-Ortiz et al. 2017; Xu et al. 2016; Baldrian 2003; Zhao et al. 2016; Marandi et al. 2008).

In general, the adsorption of metallic ions by the fungal mycelium from the aqueous solution is a complex process and highly dependent on a range of parameters such as the medium $\mathrm{pH}$, the composition of the broth, the fungal growth stage and the cells type (live, resting or dead) (Yetis et al. 2000; Baldrian 2003). Further studies are needed to further maximise the adsorption capacity of Pd onto the fungus.

\subsection{Study of the Pd biomineralisation using physico-chemical techniques}

As the morphological change to the fungal surfaces might be responsible for the adsorption of palladium, thus it was studied using FTIR. As shown in Fig. 2 (left), the difference between the FTIR-ATR spectra of $P$. chrysosporium with or without the treatment of palladium salt can be noticed. Overall, the interpretation of the FTIR data is problematic, because the fungal cell wall is composed of layers of chitin and glucans covered by proteins and the FTIR spectrum includes the combination and overlapping of characteristic bands of all these natural polymers and macromolecules (Haneef et al. 2017; Peter 2005). Moreover, chitin itself is aminoglucan which has the polysaccharide matrix of glucan with acetylamino group replacing $\mathrm{OH}$ group on the glucose monomeric ring. Hence, chitin from glucan could be distinguished only by characteristic peaks at $1641 \mathrm{~cm}^{-1}$ and $1547 \mathrm{~cm}^{-1}$ which are attributed to Amide I (C=O stretching) and Amide II (N-H bending) of acetylamino group; whereas the intensive peaks in $900-1200 \mathrm{~cm}^{-1}$ region are attributed to C-C, C-O stretching in polysaccharides and C-H stretching region in $2850-2926 \mathrm{~cm}^{-}$ ${ }^{1}$ are common for chitin, proteins, glucans and even lipids (Fig. 2, left) (Ghimire et al. 2017; 
Forfang et al. 2017; Pena et al. 2014; Gupta et al. 2011; Sastry M., Ahmad A. 2003; Iris et al. 2018). The peak intensity ratio of Amide I/Amide II falls from 2.0 to 1.6 from the control fungal sample to the $\mathrm{Pd}$ loaded fungi, indicating the disappearance of the $\mathrm{C}=\mathrm{O}$ group in comparison to the N-H bond. Thus, Pd is thought to be coordinated by NCO ligand where electron density was distributed between $\mathrm{N}$ and $\mathrm{O}$ leaving N-H bond unaffected. Moreover, another specific band for chitin associated with Amide III (complex vibrations of NHCO group) at $1315 \mathrm{~cm}^{-1}$ reduced significantly in the Pd/fungi in comparison to neat fungi (Fig. 2) (Ghimire et al. 2017). It could be hypothesized that palladium cation initially was coordinated by acetylamino group of the chitin moieties. The amount of chitin, however, in the fungal cell wall is usually no more than $45 \%$ with the rest being glucan and proteins (Peter 2005). Proteins, which cover the layers of glucan and chitin, have same Amide I and Amide II characteristic peaks as chitin and therefore are indistinguishable from the aminoglucan on the FTIR spectrum. The general action mechanism for fungus to absorb metals postulates that proteins are responsible for the formation of the nanoparticles (Sanghi et al. 2011; Syed \& Ahmad 2012; Kitching et al. 2015). Yet, the role of chitin should not be dismissed as it was found to be an effective adsorbent for metal cations (Anastopoulos et al. 2017; Să̆ 2002).

In addition to the high coordinating ability of the amides of the chitin polymer and proteins, the high adsorption capacity is also attributed to the high surface area of dense network of filamentous mycelia fungal hyphae as illustrated in the SEM image (Fig. 2, right), which was similar to the structures seen elsewhere (Vigneshwaran et al. 2006; Haneef et al. 2017). The average diameter of the dried fungal filaments is $1.3 \pm 0.1 \mu \mathrm{m}$, which is expected to expand in culture medium and could provide high surface area for Pd adsorption. The data on the fungal specific surface area determined by the BET analysis are scarce, however the cotton-wool-like fibrous fungal mycelium has recently attracted much attention as a suitable alternative for the manufactured membranes and other advanced materials (Haneef et al. 2017).

The XRD and XPS analysis of the dried P. chrysosporium biomass after the adsorption experiments confirmed the presence and loading of palladium on the surface of the fungi (Fig. 3). The X-ray diffraction (XRD) pattern of the $\mathrm{Pd} /$ fungi sample showed intense Braggs peaks corresponding to the (111), (200) and (220) lattice planes of palladium at $2 \theta=41.2,46.6$ and 67.4 degree (Fig. 3, left). The diffraction pattern shows a typical pattern for the face centered cubic (fcc) structure of palladium (JCPDS card no. 01-071-3757), this confirms the crystalline structure of Pd whereas the broad peak observed at $2 \theta=20.9$ degree is attributed to chitin. From the broadening of the pick at $2 \theta=67.4$ degree of $\mathrm{Pd}(200)$ and using the Debye/Scherrer equation, the size of the Pd nano particles was determined to be $11.3 \mathrm{~nm}$, which showed good agreement with the data from the TEM analysis.

According to the XPS analysis, it appeared that not all of the palladium on the surface of the fungi had been reduced and peaks of $\mathrm{Pd}(\mathrm{IV}), \mathrm{Pd}(\mathrm{II})$ and $\mathrm{Pd}(0)$ were identified in the spectra at 343,342 and $340 \mathrm{eV}$ (Fig. 3, right) and both $\mathrm{Pd} 3 \mathrm{~d}_{5 / 2}$ and $\mathrm{Pd} 3 \mathrm{~d}_{3 / 2}$ could be seen (Tura et al. 1988). The ratio of all the species was $\operatorname{Pd}(0): \operatorname{Pd}(\mathrm{II}): \operatorname{Pd}(\mathrm{IV})=2: 1: 1.5$ throughout the samples tested indicating that about $44 \%$ of palladium was in a reduced state whereas the rest still being in a cationic form. The presence of $\mathrm{Pd}^{2+}$ indicated that the reduction of palladium undergoes two steps where the first step $\left[\mathrm{PdCl}_{6}\right]^{4-}+2 \mathrm{e}^{-} \rightarrow\left[\mathrm{PdCl}_{4}\right]^{2-}+2 \mathrm{Cl}^{-}$is characterized by $\mathrm{E}_{0}=1.288 \mathrm{~V}$ and is therefore a limiting stage whereas the second stage $\left[\mathrm{PdCl}_{4}\right]^{2-}+2 \mathrm{e}^{-} \rightarrow \mathrm{Pd}(0)+4 \mathrm{Cl}^{-}$is less energy intensive with $\mathrm{E}_{0}=0.591$ V. Some extracellular enzymes are believed to reduce the cations of metals and stabilize the nanoparticles according to literature (Saxena et al. 2014; Syed \& Ahmad 2012; Zielonka \& 
Klimek-Ochab 2017). Thus, the synthesis of gold nanoparticles by P. chrysosporium was reported for both isolated fungal mycelium and fungus-free growth medium which were separately treated with the solution of $\mathrm{HAuCl}_{4}$ at acidic $\mathrm{pH}$ (Sanghi, Verma and Puri, 2011). After monitoring the activity of laccase, lignin peroxidase and manganese peroxidase, the authors proposed enzymatic mechanism for the formation of Au NPs where carboxylic, amino and sulfhydryl (SH) groups of the fungal proteins/enzymes played a major role in the adsorption of $\mathrm{Au}^{3+}$ ions, which were further reduced by ligninase and laccase. A further study is needed to fully investigate the role of fungal reductases and other bioactive macromolecules in the metal ions reduction, however it is clear that the fungal biomineralization of palladium, unlike Pd-synthesizing bacteria, does not require the addition of reducing agents like hydrogen and formic acid, thus significantly reducing the costs for nanoparticle production (Deplanche et al. 2014; Bennett et al. 2013; Zhu et al. 2016).

TEM analysis (Fig. 4) visualised the palladium nanoparticles on the surface of $P$. chrysosporium, which followed a normal particle size distribution with a prevailing size between 10-14 nm. Some nanoparticles agglomerated; however, the identity of each individual palladium nanoparticle was maintained. Narrow size distribution and small particle size are essential for high catalytic activity of Pd nanoparticles. Previously, both narrow and broad range in the size of the bio-derived particles have been reported. Thus, Ahmad et al. obtained Ag nanoparticles of 5-15 nm and claimed that capping of the nanoparticles with the fungal proteins prevented agglomeration in an experiment with Fusarium oxysporum (Sastry M., Ahmad A. 2003). Similar narrow range was reported by Bhainsa et al. for Ag nanoparticles obtained with Aspergillus fumigatus (Bhainsa \& D'Souza 2006). Whereas, Sanghi et al. assessed Au nanoparticles with AFM method and reported a broader size range of 10-100 nm with Phynerochaete chrysosporium (Sanghi et al. 2011). Espinoza-Ortis et al. reported the formation of needle-like tellurium nanoparticles and Se-Te particulate alloys of various morphologies with a broad size range for Te and Se-Te particles being as high as 20-465 $\mathrm{nm}$ and $50-600 \mathrm{~nm}$ respectively due to presumably agglomeration of the particles (Espinosa-Ortiz et al., 2016, 2017). Recently, P. chrysosporium was reported for the synthesis of very fine (1.5-2 $\mathrm{nm}$ in size) cadmium sulfide (CdS) quantum dots where a special stabilizing role of cysteine amino acid of the fungal proteins was investigated (Chen et al., 2014). Similarly, the binding and stabilizing properties of the fungal proteins were emphasized in the synthesis of Ag NPs formed as the result of $P$. chrysosporium mycelium treatment with silver nitrate solution, though broad range of the particles size was reported $(50-200 \mathrm{~nm})$ indicating some aggregation of metallic silver (Vigneshwaran et al., 2006).

Overall, the palladium biomineralization on the surface of $P$. chrysosporium yielded well defined palladium nanoparticles within the range of 10-14 nm which were easily characterized by different physico-chemical methods. It was deduced that only $44 \%$ of the adsorbed palladium was reduced to $\operatorname{Pd}(0)$ state whereas the reduction undergoes two steps (i.e. $\operatorname{Pd}(\mathrm{IV}) \rightarrow \operatorname{Pd}(\mathrm{II}) \rightarrow \operatorname{Pd}(0))$. Both proteins and chitin could be responsible for the adsorption of palladium and the fungal mycelium is believed to provide high surface area. Yet, further studies on the reducing activity of the fungal enzymes are required.

\subsection{Catalytic Testing of bio-derived Pd nanoparticles in Heck reaction}

A great interest in the recovery of PGMs in general and palladium in particular is due to their high catalytic activity in Suzuki and Heck coupling reactions widely used in pharmaceutical industry. The Heck reaction of stilbene synthesis seen in Fig. 5 was used to study the catalytic activity of the bio-derived palladium nanoparticles in comparison to a traditional $5 \% \mathrm{Pd} / \mathrm{C}$ catalyst (Sigma- 
Aldrich). The initial reaction rates for both catalysts were found to be comparable, $0.052 \mathrm{mmol} \mathrm{s}^{-}$ ${ }^{1}$ for $4.9 \% \mathrm{Pd} /$ fungi and $0.048 \mathrm{mmol} \mathrm{s}^{-1}$ for $5.0 \% \mathrm{Pd} / \mathrm{C}$. Although the bio-derived catalyst reached somewhat lower final conversion of $95 \%$ in $65 \mathrm{~min}$ in comparison to $98 \%$ for the $\mathrm{Pd} / \mathrm{C}$ catalyst, $\mathrm{Pd} /$ fungi demonstrated a similar performance in the studied reaction and even somewhat greater catalytic activity per unit of $\operatorname{Pd}(0)$ if taken into account that only $44 \%$ of palladium on the fungus biomass was in the reduced state. Previously, only bio-Pd obtained via bacterial route has been studied in catalytic reactions and Bennett et al. demonstrated that bacteria supported Pd maintained the same or superior activity in the Heck coupling of ethyl acrylate and iodobenzene in dimethylformamide and in the hydrogenation of 2-pentyne in comparison to commercial palladium catalysts (Bennett et al. 2013; Bennett et al. 2010). It is still not clear how bacterial support affects the nanoparticles activity though some stabilization of the nanoparticles via anchoring to the bacteria was suggested (Bennett et al. 2013). Overall, bacteria supported bio-Pd demonstrated great potential as catalyst in various chemical reactions in comparison to traditional palladium catalysts, such as $\mathrm{Pd} / \mathrm{C}$ and $\mathrm{Pd} / \mathrm{Al}_{2} \mathrm{O}_{3}$ (Macaskie et al. 2017; Zhu et al. 2016; Deplanche et al. 2014; Bennett et al. 2010). However, high costs for the production of the bacterial bio-Pd $\left(\mathrm{H}_{2}\right.$ is required) hampers the implementation of the technology. Fungal route, on the contrary, could become an economically feasible method for the production of catalytically active palladium nanoparticles via recovery of palladium from industrial effluents. In the current report, the same key catalytic properties have been demonstrated for palladium nanoparticles supported by $P$. chrysosporium, such as well defined, small size particles of 10-14 nm, 5-12\% loading of the metal and comparable to the commercial catalyst catalytic activity in a Heck reaction. Moreover, the fungal biosynthesis can be further used for the recovery of other PGMs and an example of the synthesis of platinum nanoparticles has been demonstrated with Fusarium oxysporum fungus (Syed \& Ahmad 2012).

\section{Conclusions}

The fungal biomineralization of metals reported in literature is mainly devoted to gold and silver whereas, to the best of our knowledge, this is the first report on the synthesis of catalytically active palladium NPs via a simple method of palladium adsorption from an aqueous solution onto fungus Phanerochaete chrysosporium. Overall, high surface area of the fungal support and lower production costs make the fungal biomineralization of precious metals more advantageous in comparison to bacterial biomineralization. The demonstrated method in this work opens the way for the development of fungi-based membranes to be used in cleaning industrial effluents from PGMs and at the same time converting precious metals into valuable nanoparticles.

\section{Acknowledgements}

The authors of the current paper are grateful to Dr Guy Barker, School of Life Sciences, University of Warwick, Prof Kerry Kirwan, Warwick Manufacturing Group, University of Warwick and Dr Danish Malik, Chemical Engineering Department, Loughborough University for their help and valuable advice during the project. This research is not borne out of any specific grant from funding agencies in the public, commercial, or not-for-profit sectors.

\section{References}

Addadi, L. \& Weiner, S., 2014. Biomineralization: Mineral formation by organisms. Physica Scripta, 89(9).

Anastopoulos, I. et al., 2017. Chitin adsorbents for toxic metals: A review. International Journal 
of Molecular Sciences, 18(1).

390

391

392

393

394

395

396

397

398

399

400

401

402

403

404

405

406

407

408

409

410

411

412

413

414

415

416

417

418

419

420

421

422

423

424

425

426

Baldrian, P., 2003. Interactions of heavy metals with white-rot fungi. Enzyme and Microbial Technology, 32(1), pp.78-91.

Bennett, J.A. et al., 2013. Nanoparticles of palladium supported on bacterial biomass: New reusable heterogeneous catalyst with comparable activity to homogeneous colloidal $\mathrm{Pd}$ in the Heck reaction. Applied Catalysis B: Environmental, 140-141, pp.700-707. Available at: http://dx.doi.org/10.1016/j.apcatb.2013.04.022.

Bennett, J.A. et al., 2010. Palladium supported on bacterial biomass as a novel heterogeneous catalyst: A comparison of $\mathrm{Pd} / \mathrm{Al} 2 \mathrm{O} 3$ and bio-Pd in the hydrogenation of 2-pentyne. Chemical Engineering Science, 65(1), pp.282-290. Available at: http://dx.doi.org/10.1016/j.ces.2009.06.069.

Bhainsa, K.C. \& D'Souza, S.F., 2006. Extracellular biosynthesis of silver nanoparticles using the fungus Aspergillus fumigatus. Colloids and Surfaces B: Biointerfaces, 47(2), pp.160-164.

Chen, C.C., Duh, Y.S. \& Shu, C.M., 2009. Thermal polymerization of uninhibited styrene investigated by using microcalorimetry. Journal of Hazardous Materials, 163(2-3), pp.1385-1390.

Conesa, M. et al., 2009. Root responses to soil Ni heterogeneity in a hyperaccumulator and a non-accumulator species. Environmental Pollution, 157, pp.2189-2196.

Cookson, J., 2012. The preparation of palladium nanoparticles. Platinum Metals Review, 56(2), pp.83-98.

Cueva, M.E. \& Horsfall, L.E., 2017. The contribution of microbially produced nanoparticles to sustainable development goals. Microbial Biotechnology, 10(5), pp.1212-1215.

Das, N. \& Das, D., 2013. Recovery of rare earth metals through biosorption: An overview. Journal of Rare Earths, 31(10), pp.933-943. Available at: http://dx.doi.org/10.1016/S10020721(13)60009-5.

Das, S.K., Das, A.R. \& Guha, A.K., 2010. Microbial synthesis of multishaped gold nanostructures. Small, 6(9), pp.1012-1021.

Deplanche, K. et al., 2014. Catalytic activity of biomass-supported Pd nanoparticles: Influence of the biological component in catalytic efficacy and potential application in "green" synthesis of fine chemicals and pharmaceuticals. Applied Catalysis B: Environmental, 147, pp.651665. Available at: http://dx.doi.org/10.1016/j.apcatb.2013.09.045.

Edmundson, M.C., Capeness, M. \& Horsfall, L., 2014. Exploring the potential of metallic nanoparticles within synthetic biology. New Biotechnology, 31(6), pp.572-577. Available at: http://dx.doi.org/10.1016/j.nbt.2014.03.004.

Espinosa-Ortiz, E.J. et al., 2017. Biomineralization of tellurium and selenium-tellurium nanoparticles by the white-rot fungus Phanerochaete chrysosporium. International Biodeterioration and Biodegradation, 124, pp.258-266.

Fan, X. et al., 2009. Coupling of Heck and hydrogenation reactions in a continuous compact 
reactor. Journal of Catalysis, 267(2), pp.114-120. Available at: http://dx.doi.org/10.1016/j.jcat.2009.07.019.

Forfang, K. et al., 2017. FTIR spectroscopy for evaluation and monitoring of lipid extraction efficiency for oleaginous fungi. PLOS ONE, 12(1), pp.1-17.

Gadd, G.M., 2010. Metals, minerals and microbes: Geomicrobiology and bioremediation. Microbiology, 156(3), pp.609-643.

Gherghe, S.L., 2017. Considerations about recovery of critical bio-metallurgy. E3S Web of Conferences proceedings, 18(01020), pp.1-5.

Ghimire, S. et al., 2017. Conversion of chitin isolated from fresh-water prawns to chitosan. Polymers Research Journal, 11(1), pp.1-16.

Godwin, M.A., Shri, K.M. \& Balaji, M., 2015. Engineering and Bioscience. International Journal of Research in Engineering and Bioscience, 3(5), pp.11-29.

Guil-Guerrero, J.L. et al., 2016. Antimicrobial activity of plant-food by-products: a review focusing on the tropics. Livestock Science, 189, pp.32-49. Available at: http://dx.doi.org/10.1016/j.livsci.2016.04.021.

Gupta, B.S., Hovde, P.J. \& Holme, J., 2011. Characterization of Wood Mould Fungi by FTIR A Valuable Step for Prediction of Initiation of Decay. Proceedings of DBMC XII, (3), pp.19.

Haneef, M. et al., 2017. Advanced Materials From Fungal Mycelium: Fabrication and Tuning of Physical Properties. Scientific Reports, 7(January), pp.1-11. Available at: http://dx.doi.org/10.1038/srep41292.

Heera, P. \& Shanmugam, S., 2015. Review Article Nanoparticle Characterization and Application: An Overview. Int.J.Curr.Microbiol.App.Sci, 4(8), pp.379-386. Available at: http://www.ijcmas.com.

Iris, C. et al., 2018. FTIR as an easy and fast analytical approach to follow up microbial growth during fungal pretreatment of poplar wood with Phanerochaete chrysosporium. Journal of microbiological methods, 145, pp.82-86.

Johnson Matthey, 2018. PGM Market Report February 2018, Available at: http://www.platinum.matthey.com/services/market-research/pgm-market-reports.

Kitching, M., Ramani, M. \& Marsili, E., 2015. Fungal biosynthesis of gold nanoparticles: Mechanism and scale up. Microbial Biotechnology, 8(6), pp.904-917.

Lengke, M.F., Sanpawanitchakit, C. \& Southam, G., 2011. Biosynthesis of Gold Nanoparticles: A Review. Metal Nanoparticles in Microbiology, (January), pp.37-74. Available at: http://link.springer.com/10.1007/978-3-642-18312-6_3.

Macaskie, L.E. et al., 2017. Metallic bionanocatalysts: potential applications as green catalysts and energy materials. Microbial Biotechnology, 10(5), pp.1171-1180.

Maheswari, S., Vindyashree, M. \& Murugesan, A.G., 2016. Adsorption kinetics , equilibrium and thermodynamics studies for the removal of Cadmium ( II ) Ions from aqueous solution 
by Aspergillus nidulans. , 6(4), pp.448-452.

Marandi, R., Doulati, F. \& Safaei, M., 2008. Biosorption of Lead and Zinc Ions by Phanerocheat Chrysasporium - Research on Fixed Bed Column. Conference Paper, (April 2014).

Mary, J. et al., 2018. Bio-inspired ZnS quantum dots as e ffi cient photo catalysts for the degradation of methylene blue in aqueous phase., (November).

Menon, S., S., R. \& S., V.K., 2017. A review on biogenic synthesis of gold nanoparticles, characterization, and its applications. Resource-Efficient Technologies, 3(4), pp.516-527. Available at: http://linkinghub.elsevier.com/retrieve/pii/S2405653717300489.

Moghaddam, A.B. et al., 2015. Nanoparticles biosynthesized by fungi and yeast: A review of their preparation, properties, and medical applications. Molecules, 20(9), pp.16540-16565.

Nancharaiah, Y. V., Mohan, S.V. \& Lens, P.N.L., 2016. Biological and Bioelectrochemical Recovery of Critical and Scarce Metals. Trends in Biotechnology, 34(2), pp.137-155. Available at: http://dx.doi.org/10.1016/j.tibtech.2015.11.003.

Narayanan, K.B. \& Sakthivel, N., 2011. Green synthesis of biogenic metal nanoparticles by terrestrial and aquatic phototrophic and heterotrophic eukaryotes and biocompatible agents. Advances in Colloid and Interface Science, 169(2), pp.59-79. Available at: http://dx.doi.org/10.1016/j.cis.2011.08.004.

Pena, R. et al., 2014. Ectomycorrhizal identification in environmental samples of tree roots by Fourier-transform infrared (FTIR) spectroscopy. Frontiers in Plant Science, 5(May). Available at: http://journal.frontiersin.org/article/10.3389/fpls.2014.00229/abstract.

Peter, M.G., 2005. Chitin and Chitosan in Fungi. Biopolymers Online, pp.123-132. Available at: http://doi.wiley.com/10.1002/3527600035.bpol6005.

Qin, L. et al., 2018. "Gold rush" in modern science: Fabrication strategies and typical advanced applications of gold nanoparticles in sensing. Coordination Chemistry Reviews, 359, pp.131. Available at: https://doi.org/10.1016/j.ccr.2018.01.006.

Qin, Z. et al., 2018. Extracellular biosynthesis of biocompatible cadmium sulfide quantum dots using Trametes versicolor. Journal of Biotechnology, 284(August), pp.52-56. Available at: https://doi.org/10.1016/j.jbiotec.2018.08.004.

Rawlings, D.E., Dew, D. \& Plessis, C., 2003.<Biomineralization.Pdf>., 21(1), pp.4-5.

Sağ, Y., 2002. Biosorption of Heavy Metals By Fungal Biomass and Modeling of Fungal Biosorption: a Review. Separation and Purification Methods, 30(1), pp.1-48.

Saklani, V. \& V.K. Jain, S., 2013. Microbial Synthesis of Silver Nanoparticles: A Review. Journal of Biotechnology \& Biomaterials, s13(13), pp.7-9. Available at: https://www.omicsonline.org/microbial-synthesis-of-silver-nanoparticles-a-review-2155952X.1000S13-007.php?aid=11101.

Sanghi, R., Verma, P. \& Puri, S., 2011. Enzymatic Formation of Gold Nanoparticles Using Phanerochaete Chrysosporium. Advances in Chemical Engineering and Science, 01(03), pp.154-162. Available at: 

http://www.scirp.org/journal/doi.aspx?DOI=10.4236/aces.2011.13023.

Sastry M., Ahmad A ., K.M.I. and K.R., 2003. Extracellular biosynthesis of silver nanoparticles using the fungus Fusarium oxysporum. Current Science, 85, pp.162-170. Available at: http://linkinghub.elsevier.com/retrieve/pii/S0927776502001741.

Saxena, J. et al., 2014. Emerging role of fungi in nanoparticles synthesis and their applications., 3(9), pp.1586-1613.

Siddiqi, K.S. \& Husen, A., 2016. Green Synthesis, Characterization and Uses of Palladium/Platinum Nanoparticles. Nanoscale Research Letters, 11(1). Available at: http://dx.doi.org/10.1186/s11671-016-1695-z.

Siddiqi, K.S., Husen, A. \& Rao, R.A.K., 2018. A review on biosynthesis of silver nanoparticles and their biocidal properties. Journal of Nanobiotechnology, 16(1). Available at: https://doi.org/10.1186/s12951-018-0334-5.

Syed, A. \& Ahmad, A., 2012. Extracellular biosynthesis of platinum nanoparticles using the fungus Fusarium oxysporum. Colloids and Surfaces B: Biointerfaces, 97, pp.27-31. Available at: http://dx.doi.org/10.1016/j.colsurfb.2012.03.026.

ThermoFisher Scientific, 2010. Safety Data Sheet: Sodium Borohydride,

Tura, J.M. et al., 1988. XPS and IR (ATR) analysis of Pd oxide films obtained by electrochemical methods. Surface and Interface Analysis, 11(8), pp.447-449.

Vigneshwaran, N. et al., 2006. Biomimetics of silver nanoparticles by white rot fungus, Phaenerochaete chrysosporium. Colloids and Surfaces B: Biointerfaces, 53(1), pp.55-59.

Weiner, S., 2003. An Overview of Biomineralization Processes and the Problem of the Vital Effect. Reviews in Mineralogy and Geochemistry, 54(1), pp.1-29. Available at: http://rimg.geoscienceworld.org/cgi/doi/10.2113/0540001.

Xu, P. et al., 2016. Metal bioaccumulation, oxidative stress and antioxidant defenses in Phanerochaete chrysosporium response to Cd exposure. Ecological Engineering, 87, pp.150-156. Available at: http://dx.doi.org/10.1016/j.ecoleng.2015.11.029.

Yetis, U. et al., 2000. The removal of $\mathrm{Pb}(11)$ by Phanerochaete chrysosporium. Water Research, 34, pp.4090-4100.

Zhao, M.H. et al., 2016. Toxicity and bioaccumulation of heavy metals in Phanerochaete chrysosporium. Transactions of Nonferrous Metals Society of China (English Edition), 26(5), pp.1410-1418. Available at: http://dx.doi.org/10.1016/S1003-6326(16)64245-0.

Zhao, P., Li, N. \& Astruc, D., 2013. State of the art in gold nanoparticle synthesis. Coordination Chemistry Reviews, 257(3-4), pp.638-665.

Zhu, J. et al., 2016. Selective hydrogenation using palladium bioinorganic catalyst. Applied Catalysis B: Environmental, 199, pp.108-122. Available at: http://dx.doi.org/10.1016/j.apcatb.2016.05.060.

Zhuang, W.Q. et al., 2015. Recovery of critical metals using biometallurgy. Current Opinion in Biotechnology, 33(14), pp.327-335. 


\section{Figures}

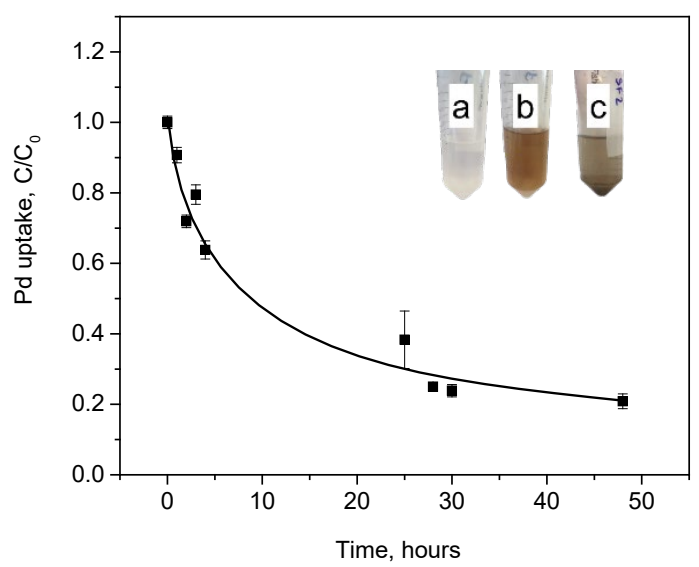

Tables

Table 1 XPS techniques (STDV based on triplicates).

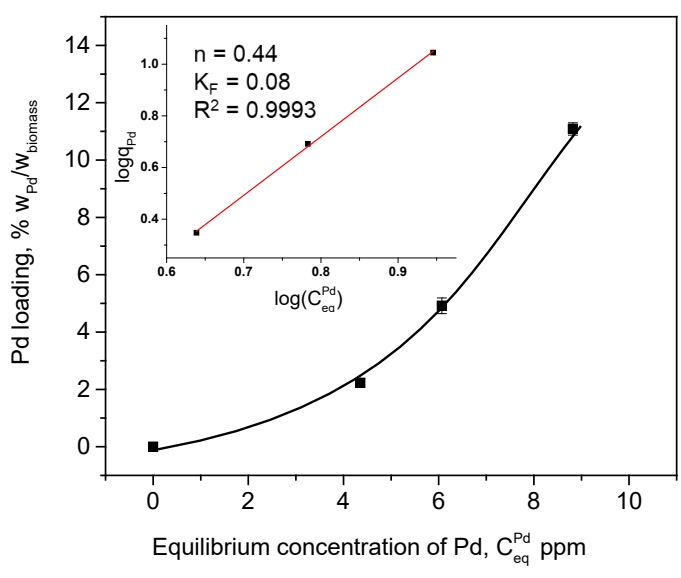

553

Fig. 1. Adsorption of $\mathrm{Pd}$ from an aqueous solution of $48 \mathrm{ppm} \mathrm{Pd}$ onto the fungus vs. time (left) and adsorption isotherm for Pd and its linearized form (right), (a - control sample with untreated fungus in the medium, $\mathrm{b}$ - after addition of $\mathrm{Pd}^{4+}$ salt solution, $\mathrm{c}-$ after 48 hours of adsorption), (20 ml total volume, $37^{\circ} \mathrm{C}, 80 \mathrm{rpm}$, Pd concentration monitored by AAS after addition into the medium with 5 days' culture of $P$. chrysosporium, 12, 24, $48 \mathrm{ppm}$ of the initial palladium concentration was tested).
Zielonka, A. \& Klimek-ochab, M., 2017. Fungal synthesis of size-defined nanoparticles Related content. Available at: https://doi.org/10.1088/2043-6254/aa84d4.

Combined data presenting a set of various adsorption experiments with different initial concentrations and final loadings of palladium onto $P$. chrysosporium determined by AAS and

\begin{tabular}{llllll}
\hline Metal form & Salt used & $\mathbf{C}^{\mathbf{0}} \mathbf{P d}, \mathbf{p p m}$ & $\mathbf{P d}_{\text {eq }}$ ads, $\%$ & $\begin{array}{l}\text { Pd load, } \\
\mathbf{\%} \mathbf{w}_{\mathbf{P d}} / \mathbf{w}_{\mathbf{b}} \text { (AAS) }\end{array}$ & $\begin{array}{l}\text { Pd load, } \\
\mathbf{\%} \mathbf{w}_{\mathbf{P d}} / \mathbf{w}_{\mathbf{b}} \text { (XPS) }\end{array}$ \\
\hline $\mathrm{Pd}(\mathrm{IV})$ & $\mathrm{K}_{2} \mathrm{PdCl}_{6}$ & 48 & $81.5 \pm 1.6$ & $12.8 \pm 0.2$ & $12.6 \pm 2.0$ \\
& & 24 & $74.5 \pm 1.4$ & $4.9 \pm 0.3$ & $6.2 \pm 1.0$ \\
& & 12 & $63.4 \pm 1.0$ & $2.2 \pm 0.1$ & $7.7 \pm 1.5$ \\
\hline
\end{tabular}



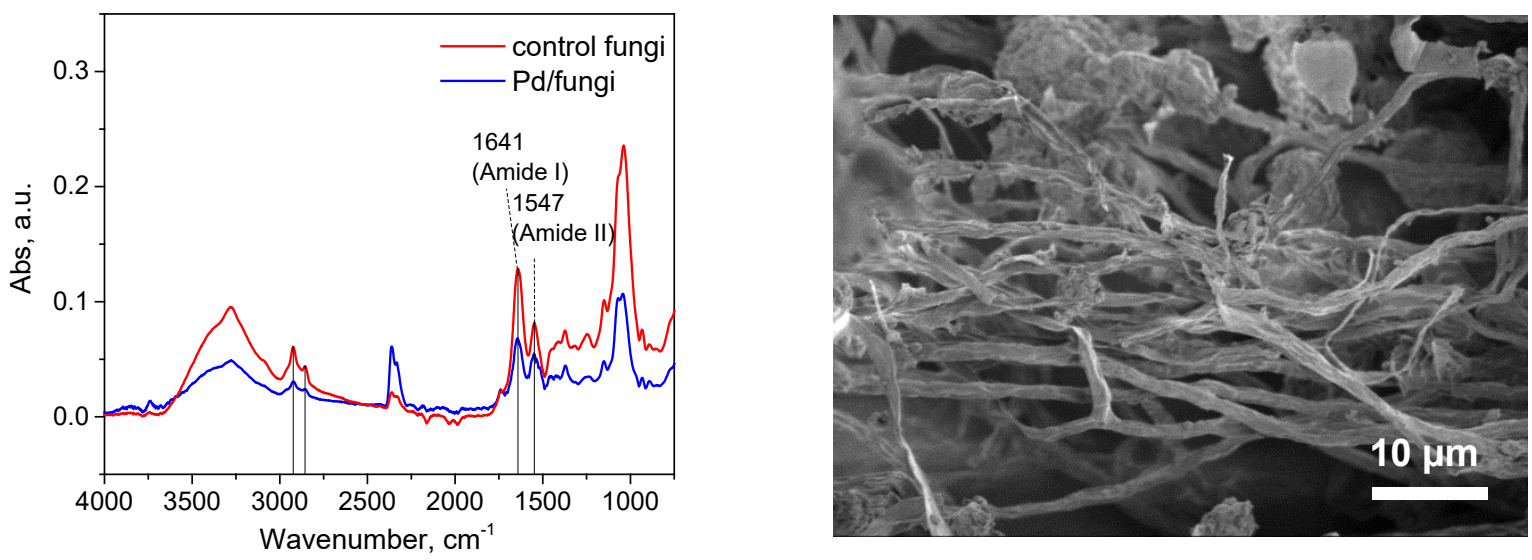

561

562 Fig. 2. Comparative FTIR spectra of the dried $P$. chrysosporium with or without Pd treatment (left) 563 and an SEM image of the fungal mycelium made of branched filaments with a diameter of $1.3 \pm 0.1$ $564 \mu \mathrm{m}$ (right).
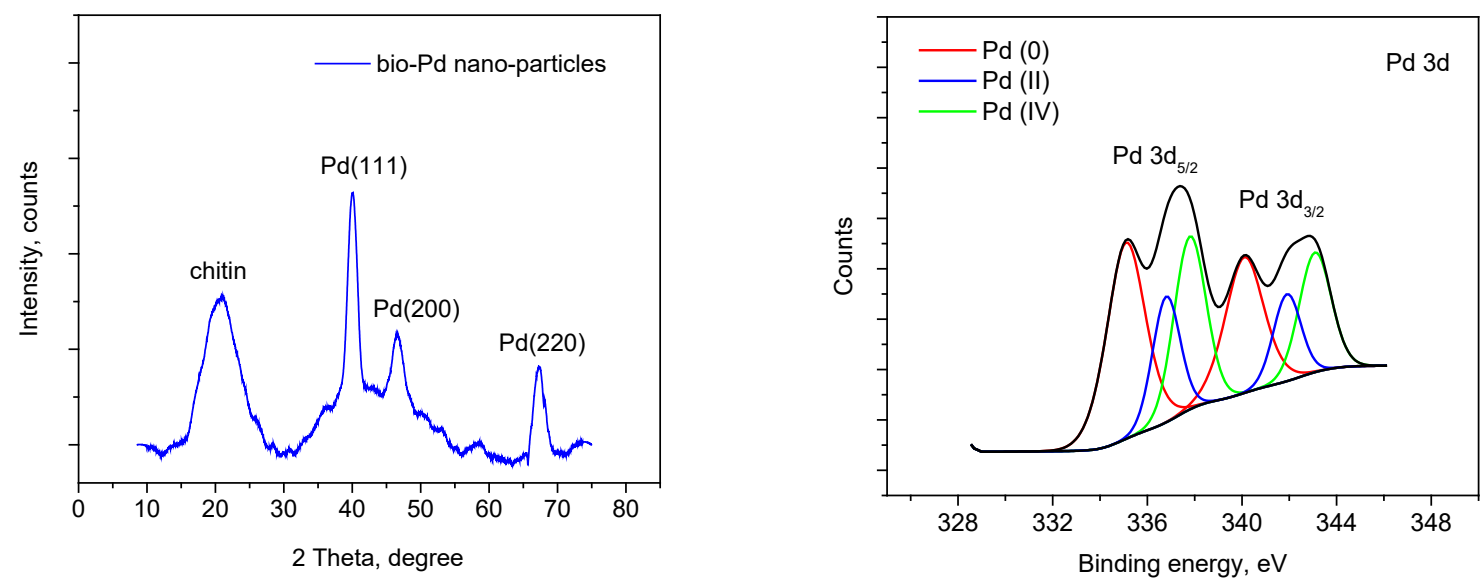

565 Fig. 3. The XRD diffraction pattern (left) and XPS spectrum of Pd 3d (right) of the $12.6 \%$ $566 \mathrm{WPd} / \mathrm{W}_{\text {fungal biomass }}$ sample. 

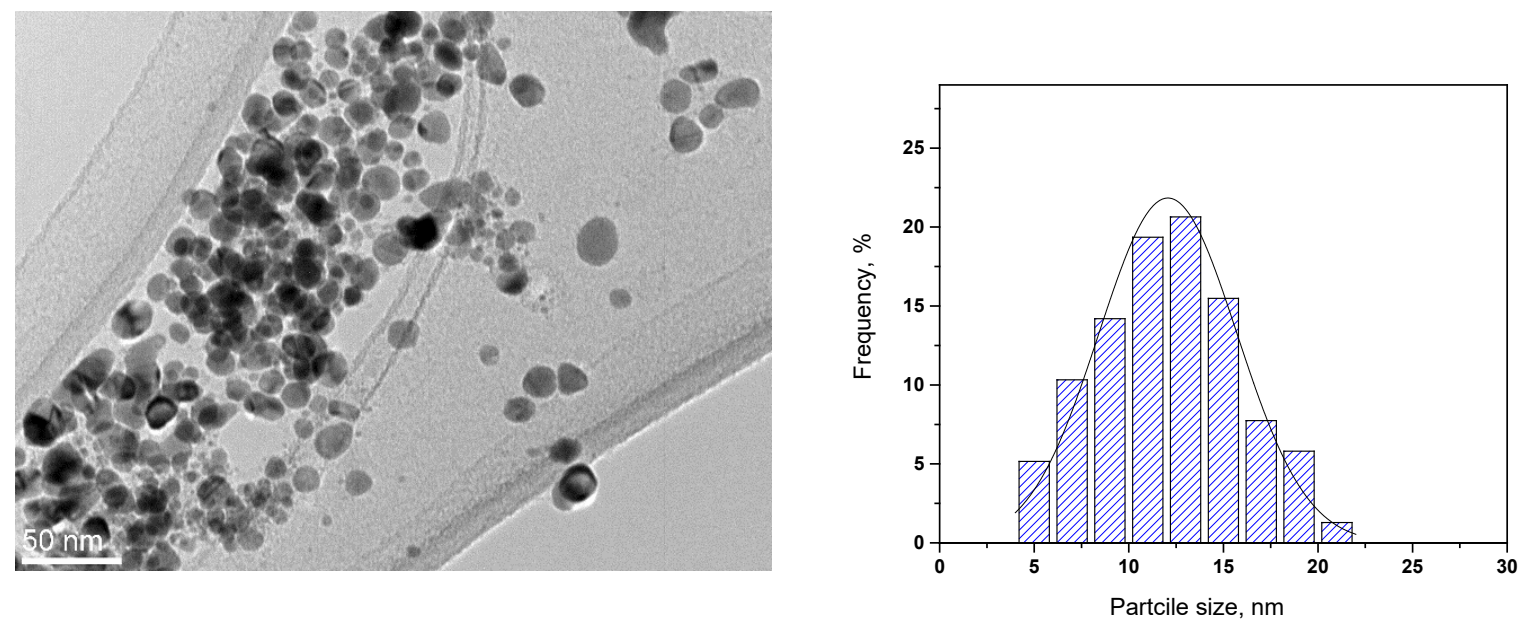

568 Fig. 4. The TEM image of the $12.6 \% \mathrm{WPd} / \mathrm{W}_{\text {fungal biomass }}$ sample (left) and the corresponding particle 569 size distribution (right).

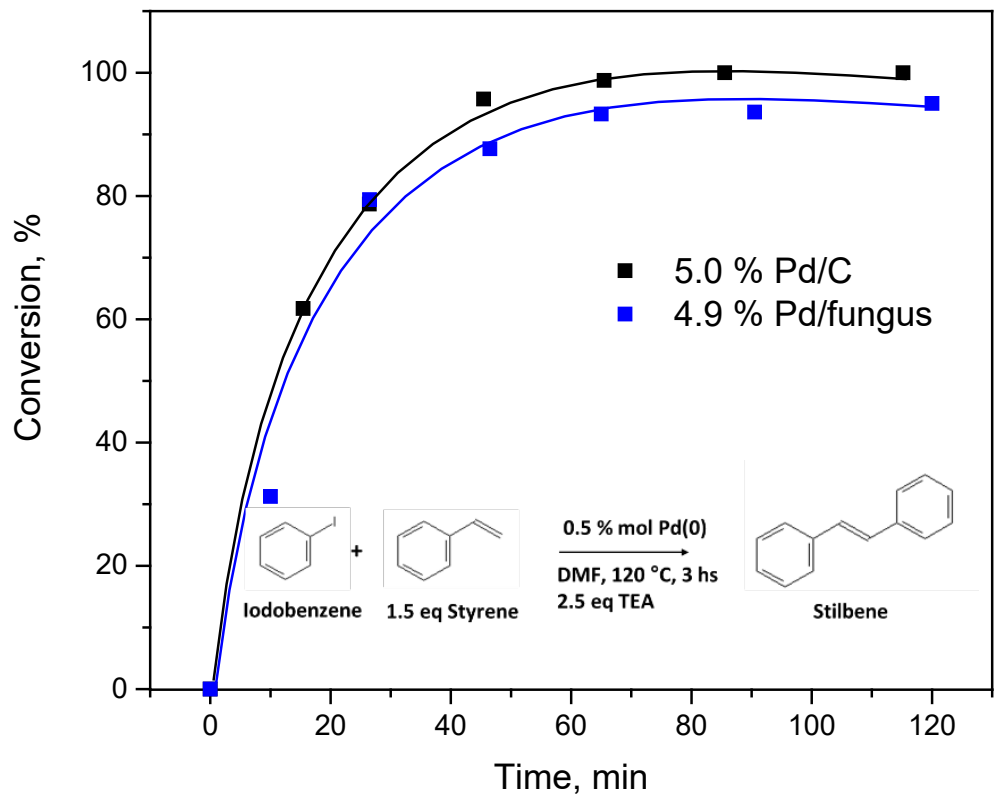

571 Fig. 5. Comparison of the rate of the Heck reaction catalysed by bio-derived palladium 572 nanoparticles and traditional $\mathrm{Pd} / \mathrm{C}$ catalyst (schematic of the Heck reaction is included). 